The gas leaving the retorts passed through an 8-in. acidproof iron pipe, insulated against heat loss by a covering of asbestos, into the bleach pot. The latter was a small acidproof iron pot packed with spiral acid-proof pottery rings. In this bleach pot a small amount of nitric acid was condensed and run off at the bottom through a 3 -in. line. The remainder of the fume passed upward through the ring packing and into the condensers proper. Wach condenser consisted of nine 6-in. acid-proof iron pipes comprising nine lengths of pipe $5 \mathrm{ft}$. long, connected at the ends by return bend fittings so as to form a continuous vertical coil $6 \mathrm{ft}$. wide and $8 \mathrm{ft}$. high. These were sprayed by cooling water on the outside for condensation of the fume to nitric acid. The pipes comprising the condenser were inclined in such a way that all acid condensed ran off through the bleach pot, where the action of the hot gases drove off the lower oxides of nitrogen brought down in the condensation, resulting in the bleaching or lightening in color of the product. The remainder of the gas, consisting of residual air in the retort and all lower oxides of nitrogen, passed from the condenser through tile lines into hyponitric towers. The latter, of which there were eighteen to each unit arranged in two parallel lines of nine towers each, consisted of 30 -in. chemical stoneware sections resting in acidproof iron dishes (Fig. 1).

There were six tower sections to each tower and all were packed with spiral chemical rings. The flow of gas was in series through these towers. Water was started from the top of Tower 18 and was pumped over each tower in turn in series, countercurrent to the flow gas. In this countercurrent circulation the water gradually adsorbed the acid in the gases, coming off at Tower 1 as weak nitric acid. The gases leaving
Tower 18 escaped to the atmosphere practically free of nitric acid.

The acid from the condensers and bleach pots flowed through acid coolers, which consisted of loops of 2-in, acidproof iron pipe immersed in a trough of water, and from the coolers passed directly into the mixing tanks.

Each unit was provided with three mixing tanks, of steel plate construction, $8 \mathrm{ft}$. in inside diameter, $30 \mathrm{ft}$. long, and with a 2 -in. lining of acid-proof radial brick. These tanks were so connected that each could draw oleum from the oleum tank, weak nitric acid from the weak acid tanks, or strong acid direct from the strong acid lines.

In mixing, the proper amount of oleum from the oleum storage tank was led into the mixing tank and followed by weak or strong nitric acid in the proportions necessary to give the mix desired. The mixing tanks were provided with motordriven agitators in order to provide a uniformly mixed product, and there was also provided a circulating pump which drew the acid from the tank through a cooler and returned it to the same tank. This acid cooler consisted of a coil of five lengths of 6 -in. acid-resisting iron pipe sprayed with water.

During the period of operation there was an average of $7200 \mathrm{lbs}$. of nitrate per retort charge. It was found that, after the difficulties always incident to the starting of a new plant were overcome, it was possible to get about two and one-half charges per retort per $24 \mathrm{hr}$. day, and, had the plant continued to run on this schedule, could doubtless have been kept up with such retorts as were in operation.

Including the starting-up period, the yield of nitric acid per $100 \mathrm{lbs}$. of sodium nitrate was approximately $65 \mathrm{lbs}$. The sulfuric acid ratio to sodium nitrate was slightly less than $1: 1$.

\section{Short Method for the Ultimate Analysis of Coal:}

\author{
By S. W. Parr
}

UNYVERSTY OF IEZINOIS, URBANA, IKZLNOIS

$\mathrm{F}$ OR purposes of the engineer in boiler testing, the following method for determining the carbon, hydrogen, and oxygen in coals has been in practical use for a number of years with very satisfactory results.
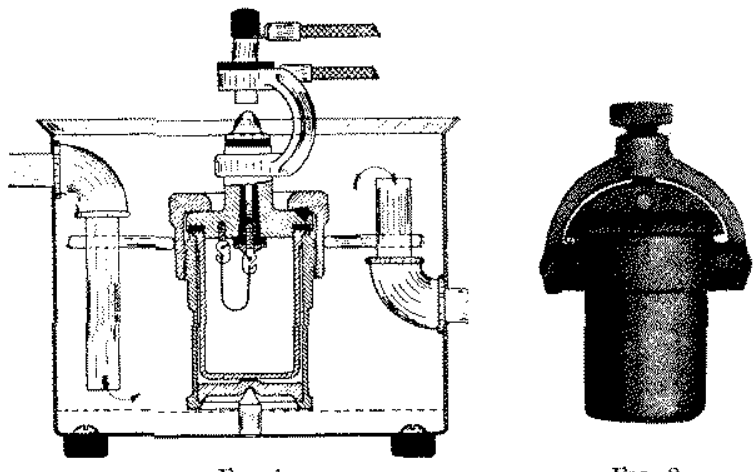

FixG. 1

FIG, 2

An ordinary combustion of the coal is made with sodium peroxide by use of the calorimetric bomb or similar devices, especially adapted to total carbon or sulfur determination, as shown in Figs. 1 or 2. The carbonate formed is discharged

1 Presented before the Division of Industrial and Engineering Chemistry at the 63rd Meeting of the American Chemical Society, Birmingham, Ala., Aptil 3 to 7,1922 . in any apparatus suitable for accurately measuring the carbon dioxide as shown in Fig. 3.

Having now the values in hand for sulfur and B.t. u., the calculations are of a simple order.

ULTIMATE ANAEXSIS OF COAT

\section{MoISTURE FreE}

i. Weight of sulfur $\times 2777=$ Catories from sutfur as $\mathrm{Fe} \mathrm{S}_{2}$.

2. Weight of carkon $\times 8080=$ Caloties from carbon.

3. Total determined calories $-(1+2)$ - Calories from available hydrogen.

4. Caloties from available hydrogen $=$ 34,450
Weight of available hydrogen.

5. Nitrogen present may be assumed as a coustant of 1.25 per cent.

6. Thea, by difference, $100-(S+$ $\mathrm{C}+\mathrm{H}+\mathrm{N}+$ ash as weighed $)=(\mathrm{O}+$ C +
iT).$^{2}$

7. $8 / 9(\mathrm{O}+\mathrm{H})=$ Total axygen.

8. $1 / 9(\mathrm{O}+\mathrm{H})=$ Combined hydrogen.

9. Then, combined hydrogen + available hydrogen $(8+4)=$ Total hydrogery.

By deriving the factors as thus indicated, we have all of the constituents as obtained by ultimate analysis and with a degree of accuracy entirely commensurate with that secured by the longer process.

2 The expression $(O+H)$ refers to the total oxygen plus that amount of hydrogen necessary to combine with it to form water. This hydrogen is referred to as "combined hydrogen" to differentiate it from the "avaitable hydrogen." 